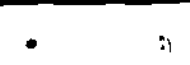

Chemistry - General

AEC Research and Development Report

\title{
REACTIONS OF HYDROGEN PEROXIDE AND ION EXCHANGE RESINS
}

\author{
by
}

E. W. Baumann

Pile Engineering Division

April 1960

E. I. du Pont de Nemours \& Co.

Savannah River Laboratory

Aiken, South Carolina 
This report was prepared as an account of Government sponsored work. Neither the United States, nor the Commission, nor any person acting on behalf of the Commission:

A. Makes any warranty or representation, expressed or implied, with respect to the accuracy, completeness, or usefulness of the information contained in this report, or that the use of any information, apparatus, method, or process disclosed in this report may not infringe privately owned rights; or

B. Assumes any liabilities with respect to the use of, or for damages resulting from the use of any information, apparatus, method, or process disclosed in this report.

As used in the above, "person acting on behalf of the Commission" includes any employee or contractor of the Commission, or employee of such contractor, to the extent that such employee or contractor of the Commission, or employee of such contractor prepares, disseminates, or provides access to, any information pursuant to his employment or contract with the Commission, or his employment with such contractor.

Printed in USA. Price $\$ 1.00$

Avallable from the office of Technical Services

U. S. Department of Commerce

Washington 25, D. C. 



\section{ABSTRACT}

The interaction of dilute aqueous $\mathrm{H}_{2} \mathrm{O}_{2}$ and Ion exchange resins was investigated. A mechanism of absorption and decomposition of $\mathrm{H}_{2} \mathrm{O}_{2}$ on anion exchange resin is proposed. 


\section{CONTENTS}

List of Tables and Figures 4

Introduction 5

Summary

Conclustons 6

Discussion $\quad 7$

I. Background 7

A. Properties of Hydrogen Peroxide 7

B. Properties of Ion Exchange Resins 7

C. Scope of Investigation 8

II. Hydrogen Peroxide Solutions 0.05M or Greater 8

A. Reaction with Different Resins 8

Bepeated Contact of IRA-400-OH with $0.05 \mathrm{M}$
Hydrogen Peroxide

C. Effect on Resin Matrix 11

III. Hydrogen Peroxide Solutions Less than 0.05M 11

IV. Decomposition of Hydrogen Peroxide Absorbed by
Anion Exchange Resin

A. "Amberlite" IRA-400-OH and XE-150 13

B. Decomposition in Presence of Other Resins 14

V. Mechanism of Hydrogen Peroxide Absorption on IRA-400-OH 15

A. Removal of Hydrogen Peroxide from IRA-400-OH 15

B. Absorption from Solution; Equilibrium Quotient 16

C. Effect on $\mathrm{pH} \quad 16$

VI. Hydrogen Peroxide Removal by Resins in a Miniature Purification Loop

Appendix

I. Preparation and Analysis of Resins 18

II. Preparation and Analysis of Hydrogen Peroxide Solutions 19

III. Method for Chemical Oxygen Demand 19

Bıliography 20 


\section{LIST OF TABLES AND FIGURES}

Tables

$\underline{\text { Page }}$

I Effect of Hydrogen Peroxide on Ion Exchange Resins

21

II Release of Organic Matter from Resin by Peroxide Treatment

III Kinetic Data for Decomposition of Hydrogen Peroxide Absorbed on Resins

IV Influence of Other Resins on Decomposition of

Hydrogen Peroxide Absorbed on IRA-400-OH

22

$\mathrm{V}$ Washing of Hydrogen Peroxide from IRA-400-OH

VI Equilibrium Absorption of Hydrogen Peroxide on IRA $-400-\mathrm{OH}$

VII Hydrogen Peroxide Removal by Resins in a Miniature Purification Loop

24

\section{Figures}

1 Repeated Treatment of IRA-400-OH with $0.05 \mathrm{M}$ Hydrogen Peroxide

Hydrogen Peroxide Solution in Contact with IRA-400-OH

3 Material Balance of Hydrogen Peroxide in Resin-Solution Mixtures

4 Hydrogen Peroxide Solution in Contact with IRA-400-OH

5 Hydrogen Peroxide Solution in Contact with Various Resing

6 Decomposition of Hydrogen Peroxide Absorbed on IRA $-400-\mathrm{OH}$

7 Decomposition of Hydrogen Peroxide Absorbed on XE-150

$8 \quad$ pH of Resin Slurry 


\section{REACTIONS OF HYDROGEN PEROXIDE AND ION EXCHANGE RESINS}

\section{INTRODUCTION}

Hydrogen peroxide, a product of the radiolytic decomposition of water, is present in water from nuclear reactors. When water of high purity is maintained, the concentration of peroxide, though only a few parts per miliion, may be many times that of other impurities. Thus peroxide, the major impurity, may affect the performance of the ion exchange resins used for purification.

Several reactions appear possible. The peroxide may oxidize the resin matrix or destroy the exchange groups. It may be absorbed by the resin. On the other hand, at these low concentrations the peroxide and the resin may not interact at all.

Reactions of hydrogen peroxide and ion exchange resins are mentioned only briefly in the literature. An experiment by Rynasiewicz (1) indicated that the anion exchange resin absorbs hydrogen peroxide, but no detalled investigation was made. Conflicting information is reported from an NRX loop at Chalk River: although peroxide was removed by the resins at one time(2), at another time it was not removed ${ }^{(3)}$, the latter observation being confirmed in their laboratory. Workers at Westinghouse $(4)$ reported nearly quantitative removal of peroxide when a decontaminating solution containing peroxide was passed through a bed of mixed resin. Wood(5) reported that $50 \%$ peroxide degraded a cation exchange resin, and that the degradation was catalyzed by the presence of iron or copper.

The purpose of the present investigation was to determine the interactions of ion exchange resins and hydrogen peroxide in order to predict the effect of dilute peroxide on resin performance.

\section{SUMMARY}

The interaction of the following resins with peroxide was investigated: "Amberlite" * IR-120-H, IRA-400-OH, IRA-400- $\mathrm{CO}_{3}$, IRA-400- $\mathrm{HCO}_{3}$, IRA-400-Cl, and XE-150. Of these only IRA-400-OH and XE-150 (a mixed resin that contains purified IRA $400-0 H$ ) reacted appreciably with dilute peroxide, although some damage to the resin matrix of IR-120-H occurred with $30 \% \mathrm{H}_{2} \mathrm{O}_{2}$. Up to $15 \%$ of the strongly basic exchange sites in IRA-400-OH could be converted to weakly basic sites by repeated contact with $0.05 \mathrm{M} \mathrm{H}_{2} \mathrm{O}_{2}$.

In addition to the chemical attack observed, peroxide was absorbed by IRA-400, especially in the hydroxide form, even from very dilute $\left(10^{-4} \mathrm{M}\right)$ solutions. This was apparently an ion exchange process in

* Trademark, Rohm and Haas Company, Philadelphia, Pennsylvania. 
which the resin was converted to the hydroperoxide form. The equilibrium quotient was about 1.5 at $25^{\circ} \mathrm{C}$. The absorbed peroxide decomposed with the evolution of $\mathrm{O}_{2}$ and the regeneration of the hydroxide form.

The decomposition was first order at concentrations above about 0.2 mole $\mathrm{H}_{2} \mathrm{O}_{2}$ /equivalent of resin. Below this, the rate increased abruptly, and no kinetic interpretation was attempted. The half-life of the first order decomposition at $30^{\circ} \mathrm{C}$ was 0.7 hour for IRA-400-OH and 1.6 hours for XE-150. The apparent activation energy was about $20 \mathrm{kcal} / \mathrm{mole}$ for both resins.

The laboratory observation that only the hydroxide form of the resin absorbed peroxide to any great extent was confirmed in a miniature purification loop. When irradiated water was passed through beds of mixed resin in the $\mathrm{H}-\mathrm{OH}$ and $\mathrm{H}_{-} \mathrm{CO}_{3}$ forms, peroxide was removed only by the $\mathrm{H}-\mathrm{OH}$ bed.

\section{CONCLUSIONS}

1. Peroxide concentrations of a few ppm, such as would occur in irradiated water, will not harm ion exchange resins or affect the ion exchange process to any great extent. The anion resin in the hydroxide form will remove the peroxide; the absorbed peroxide will decompose, stolchiometrically releasing oxygen and regenerating hydroxide resin. This means that some gassing will occur in the column; at higher concentrations of peroxide this gassing might affect column operation.

2. Significant amounts of products other than $\mathrm{O}_{2}$, such as $\mathrm{CO}_{2}$, will not be produced, although trace amounts of organic materlal may be released which could produce $\mathrm{CO}_{2}$ through subsequent irradiation.

3. The ablilty of the column to remove other ions will be affected slightly, if at all, by the presence of peroxide in the system, since the affinity of the resin for peroxide is less than that for most other anions.

4. As the column becomes saturated with other anions its ability to remove peroxide by ion exchange will decrease. Therefore the peroxide content of the solution may increase, although the presence of absorbed metal ions may catalyze peroxide decomposition and effect removal in this way.

5. The net result of a process in which peroxide is formed by radiolysis of water and then removed by ion exchange will be to produce stolchiometric amounts of hydrogen and oxygen from the water. 


\section{DISCUSSION}

\section{BACKGROUND}

A. Properties of Hydrogen Peroxide

There are several properties of hydrogen peroxide that may contribute to its action with ion exchange resins $(6)$. The first is its ability to act either as an oxidizing or a reducing agent; it is more powerful as an oxidizing agent. It is a stronger oxidizing agent in acid than in base.

The second important property of hydrogen peroxide is its ability to decompose, in the presence of impurities, with the evolution of oxygen and with no apparent action on the impurity, which catalyzed the decomposition*. The reaction is

$$
2 \mathrm{H}_{2} \mathrm{O}_{2} \rightarrow 2 \mathrm{H}_{2} \mathrm{O}+\mathrm{O}_{2}
$$

The third important property of hydrogen peroxide is its weakly acldic nature. It ionizes according to the equation:

$$
\mathrm{H}_{2} \mathrm{O}_{2} \rightleftarrows \mathrm{H}^{+}+\mathrm{HO}_{2}^{-}
$$

The dissociation constant is $2.24 \times 10^{-12}$ at $25^{\circ} \mathrm{C}$.

\section{B. Properties of Ion Exchange Resins}

The ion exchange resins used in this work were "Amberlite" IR-120, which is a cation exchange resin, "Amberlite" IRA-400, which is an anion exchange resin, and "Amberlite" XE-150, which is a specially purified mixture of equivalent amounts of the other two resins. The matrix of each is a copolymer of polystyrene and divinylbenzene. The cation resin has as its active group a sulfonic acid group ( $-\mathrm{SO}_{3} \mathrm{H}$ ); the anion resin has a quaternary ammonium group $\left(-\mathrm{CH}_{2} \mathrm{~N}\left(\mathrm{CH}_{3}\right)_{3} \mathrm{OH}\right)$. Both resins are essentially insoluble in water, in which they are considered completely ionized. Rapid exchange of lons can occur between the resin and solution. In the vicinity of a wet resin regenerated to the hydrogen or hydroxide form, there is a strongly acld or alkaline, region.

The methods for preparing the resins and determining their exchange capacities are summarized in the Appendix. The IR-120 was used only

* Because of the effect of impurities in promoting decomposition, a study of the kind reported here is subject to side effects caused by impurities in the materials used. This means that the numbers reported here may not be definitive. It is believed that the conclusions and the orders of magnitude of the numbers are generally applicable. 
in the hydrogen form. The IRA-400 was used in the hydroxide, carbonate, bicarbonate, and chloride forms. The XE-150 consisted of equivalent amounts of the hydrogen and hydroxide resins, and was used as received from the manufacturer.

\section{Scope of Investigation}

Two major effects were considered. The first was the action of hydrogen peroxide upon the resin, which may result in loss of resin exchange capacity or damage to the resin structure. This can be studied by using "concentrated" peroxide solutions (which are defined here as greater than $0.05 \mathrm{M}$ ). While resin in contact with irradiated water will probably not be subjected to peroxide concentrations of this magnitude, the results of the experiments with these

"concentrated" solutions will indicate the limit of damage that can occur by repeated contact of resins and dilute hydrogen peroxide.

The second effect was that of the resin on the hydrogen peroxide. This is best seen when a very dilute peroxide solution is used (a few parts per million) where the effect of peroxide on the resin will be slight. The results demonstrated what the action of ion exchange resins would be with regard to removal of hydrogen peroxide from irradiated water.

Results from studies of these two effects indicated that the peroxide was absorbed by the hydroxide resin and then decomposed. This decomposition was studied in detail, and from the results a mechanism of absorption and decomposition was formulated.

\section{HYDROGEN PEROXIDE SOLUTIONS O.05M OR GREATER}

\section{A. Reaction with Different Resins}

The first step in the investigation was to determine the interaction of $0.05 \mathrm{M} \mathrm{H}_{2} \mathrm{O}_{2}$ with "Amberlite" IR-120-H, IRA-400-OH, IRA-400- $\mathrm{CO}_{3}$, IRA-400- $\mathrm{HCO}_{3}, \mathrm{XE}-150$, and polystyrene beads. Th1s concentration was chosen because $1 t$ was belleved this would not degrade the resin beyond what could reasonably occur with a more dilute solution, whose effects were ultimately sought. The results from these experiments defined the resins that might interact with dilute peroxide.

Experimental -- One or two grams of the resin were placed in a flask with $100 \mathrm{ml} 0.05 \mathrm{M} \mathrm{H}_{2} \mathrm{O}_{2}$ and remained there for two hours at room temperature. At the end of this time, the resin and solution were separated. The peroxide content of the solution and the salt-splitting capacity of the resin were determined as described in the Appendix.

Results and Discussion -- The results are given In Table I. Little or no. effect was observed with the IR-120-H, either with 
regard to capacity loss or change in peroxide content of the solution. The IRA-400-OH, on the other hand, lost $9 \%$ of its salt-splitting capacity, and the peroxide in solution had completely disappeared at the end of two hours. Gassing was observed in this mixture after an Induction period of about two minutes, and it appeared to originate on the resin particles. The gas, later identified as oxygen, came from decomposition of peroxide. The IRA-4nO- $\mathrm{CO}_{3}$ and IRA-400- $\mathrm{HCO}_{3}$ did not decrease in capacity, and the peroxide in solution decomposed to only a slight extent in their presence. The decomposition of the peroxide in contact with XE-150, attributed to the presence of the hydroxide form of the anion resin in this resin mixture, would have eventualiy gone to completion had the contact between the resin and solution been prolonged. The polystyrene beads served as blanks for this experiment, and their presence did not affect the peroxide content of the solution.

B. Repeated Contact of IRA-400-OH with $0.05 \mathrm{M}$ Hydrogen Peroxide

Since the IRA $-400-0 H$ was the only resin that seemed to affect and be affected by the $0.05 \mathrm{M}$ peroxide, further work was done to determine the extent of degradation attainable by a peroxide solution of this concentration.

\section{Reaction with IRA $-400-\mathrm{OH}$}

Experimental -- Two grams of IRA-400-OH were repeatedly treated with $0.05 \mathrm{M} \mathrm{H}_{2} \mathrm{O}_{2}$ in a batch process in which the resin and $100 \mathrm{ml} \mathrm{H} \mathrm{H}_{2}$ were allowed to stand two hours, the resin and solution separated, fresh peroxide added, and the process repeated until a designated number of treatments had been made. Then the final solution was analyzed for peroxide content, and the ultimate and salt-splitting capacities of the resin were determined as described in the Appendix.

Results and Discussion -- The results are shown in Figure 1. Virtually all the peroxide had disappeared from the solution within two hours in every case. About $15 \%$ of the salt-splitting capacity was lost, after which little further change occurred. The ultimate capacity was essentially unchanged throughout. This implies that the "strong base" (quaternary ammonium) group is converted to a "weak base" (perhaps tertiary amine) group. The resin lost some of its ion exchange ability in that the weak base groups cannot absorb weak acids or split salts. They can, however, absorb strong acids.

\section{Reaction with Thermally Treated IRA-400-OH}

Since conversion of strong base to weak base groups was observed previously in resin that had been heated to $90^{\circ} \mathrm{C}$ for several days $(7)$, it was of interest to conduct an experiment to see if the same groups were converted by the thermal and the peroxide treatments. That is, 
If this were the case, heating the resin would eliminate the strong base groups vulnerable to attack by peroxide. Thus no decrease in strong base groups would result from the peroxide treatment of the heat-treated resin.

Experimental -- IRA-400-OH was pretreated by heating it in a closed tube in an oven at $90^{\circ} \mathrm{C}$ for 69 hours. The resin was not allowed to go dry during this time. Then samples of resin were treated repeatedly with $\mathrm{H}_{2} \mathrm{O}_{2}$ as described above.

Results and Discussion -- The results, Figure 1, show that, although there was a significant decrease in salt-splitting capacity from the heat treatment, it did not eliminate the strong base groups subject to peroxide attack. The heat-treated resin lost about as many strong base groups per unit welght as did the untreated resin. On the basis of these results it was concluded that some exchange sites are vuinerable to thermal attack and others to chemical (peroxide) attack.

\section{Products of Reaction}

\section{a. Organic Material}

In the degradation of exchange sites of IRA-400-OH, some organic material is probably released to the solution. For example, if the Hofmann degradation occurred, as shown by the following equation:

$$
\mathrm{R}-\mathrm{CH}_{2}-\mathrm{N}\left(\mathrm{CH}_{3}\right)_{3} \mathrm{OH} \rightarrow \mathrm{R}-\mathrm{CH}_{2} \mathrm{~N}\left(\mathrm{CH}_{3}\right)_{2}+\mathrm{CH}_{3} \mathrm{OH}
$$

methyl alcohol would be released. An attempt was made to determine how much organic material was released during the repeated treatment of resin with peroxide described above. This was done by determining the chemical oxygen demand of the supernate by the method described In the Appendix. The method is neither precise nor accurate, but the results, shown in Table II, do indicate that more organic material is released by peroxide treatment than by a water wash.

$$
\text { b. Gas }
$$

The gas released during the reaction was identified as oxygen, although $\mathrm{CO}_{2}$ was also considered a possible product from the reaction of peroxide with these organic resins. A qualitative analysis by mass spectrograph of the gas released in the reaction did not reveal any $\mathrm{CO}_{2}$ other than that attributable to a small amount of air in the sample. An alternate fate of released $\mathrm{CO}_{2}$ could be its absorption by the IRA-400-OH, with the formation of bicarbonate resin. However, no release of $\mathrm{CO}_{2}$ on acidification of the resin was detected in an absorption train containing "Ascarite". Also, the characteristic inflection point for bicarbonate was absent in titration curves of the peroxide-treated resin. 


\section{Effect on Resin Matrix}

No change in the structure of the resin matrix could be detected from the infrared spectra of IRA-400-OH and IR-120-H after treatment with $0.05 \mathrm{M} \mathrm{H}_{2} \mathrm{O}_{2}$. Another sample of IRA-400-OH was treated with $30 \% \mathrm{H}_{2} \mathrm{O}_{2}$, but still no structural change was detected. The infrared spectrum of IR-120-H that had been treated with $30 \% \mathrm{H}_{2} \mathrm{O}_{2}$, however, showed a greater number of "bonded hydroxyl groups", as if some oxidation of the resin, to form hydroxyl groups, had taken place.

Another method to detect possible structural damage was tried: namely, that of measuring the water uptake of resin before and after treatment. If the matrix structure were attacked, a decrease in the degree of crosslinking would probably result, and the water uptake of the resin would increase. One-gram samples of IR-I2O-H and IRA-400-OH were left in contact with $10 \mathrm{ml} 30 \% \mathrm{H}_{2} \mathrm{O}_{2}$ overnight; the resin and solution were separated by filtration. The water uptake of the resins so treated was determined by allowing them to come to equilibrium at room temperature in an atmosphere saturated with water vapor. The wet weight of the peroxide-treated IR-120-H was $6.3 \%$ greater than that of the untreated resin; that of the treated IRA-400-OH was only $1.5 \%$ greater.

The results from both the infrared spectral analyses and the water uptake measurements, then, indicate that the matrix of IR-120-H is attacked to some extent by concentrated $\mathrm{H}_{2} \mathrm{O}_{2}$, but that of the IRA-400-OH slightly, if at all. This is in keeping with the fact, noted earlier, that peroxide is a better oxidizing agent in acid than in basic media. In addition, in the anion resin the exchange sites are probably more vulnerable to attack than is the resin structure.

\section{HYDROGEN PEROXIDE SOLUTIONS LESS THAN 0.05M}

After the effect of the peroxide on the resin had been established, the action of the resin on the peroxide was investigated. This was done by placing resin in contact with solutions so dilute that the damage to the resin would be negligible. Any effect of the resin on peroxide in solution, on the other hand, would be manifest. The resins used in this study were "Amberlite" IR-120-H, IRA-400-OH, IRA $-400-\mathrm{CO}_{3}$, IRA $-400-\mathrm{HCO}_{3}$, IRA $-400-\mathrm{Cl}$ and $\mathrm{XE}-150$.

Experimental -- Twenty-five $\mathrm{ml}$ of dilute $\mathrm{H}_{2} \mathrm{O}_{2}$ were stirred with $0.74 \mathrm{ml}$ resin for various lengths of time at room temperature. Then resin and solution were separated, and the peroxide content of the solution was determined colorimetrically as described in the Appendix: In addition, the IRA -400 resins were washed with $1 \%$ $\mathrm{H}_{2} \mathrm{SO}_{4}$ to remove the absorbed peroxide, as was done by Rynasiewicz ${ }^{(1)}$. The peroxide content of the wash was determined colorimetrically. Little, if any, of the peroxide could be removed from the resin by water wash, a fact that will be discussed in more detail in section $V$. 
This batch method with stirring does not, of course, duplicate performance of ion exchange columns. It was adopted as an experimental method to eliminate problems introduced by gassing and other variables inherent in column operation.

Results and Discussion -- In Figure 2 the peroxide contents of the solution and resin phases are presented as a function of contact time for IRA-400-OH and peroxide solutions of various concentrations. At every concentration, the peroxide content of the resin phase rapidly reached a maximum, then decreased slowly. During the same intervals the peroxide content of the solution decreased abruptiy, then more slowly. Summation of the peroxide content of the two phases did not produce a material balance, as shown in Figure 3.

This behavior is interpreted as a rapid absorption by the resin phase, to equilibrium, followed by an attempt to maintain equilibrium between the two phases as the peroxide decomposed. Subsequent experiments, described in Section IV, revealed that the peroxide decomposed after It was absorbed into the resin phase. Hence the resin apparently continuously absorbs peroxide from solution, to maintain its peroxide content as decomposition proceeds.

In Figure 4 two other curves are compared with that for $0.5 \mathrm{~g}$ IRA-400-OH In $25 \mathrm{ml} 10^{-4} \mathrm{M} \mathrm{H}_{2} \mathrm{O}_{2}$. One illustrates that when the amount of resin relative to the amount of solution was increased, the rate of disappearance of peroxide from solution was increased, which would be expected if the resin were acting as the agent for removal. The other shows that a resin that has been pretreated with $30 \% \mathrm{H}_{2} \mathrm{O}_{2}$ absorbed peroxide from a $10^{-4} \mathrm{M}$ solution somewhat more slowly than the untreated resin.

Disappearance of peroxide from solution in contact with resins other than IRA-400-OH occurred to a lesser extent, Figure 5. The peroxide content of the solution in contact with "Amberlite" IR-120-H decreased slightly and then leveled off, but no peroxide could be recovered from the resin. The mixed resin, XE-150, probably because of its hydroxide resin content, absorbed peroxide. Here the rate was slower than that for the hydroxide resin alone since a smaller amount of hydroxide resin was present. The various forms of IRA-400 affected the peroxide content in the following order:

$$
\mathrm{OH}^{-} \gg \mathrm{CO}_{3}^{-}>\mathrm{HCO}_{3}^{-}>\mathrm{CI}^{-}
$$

In the experiments with carbonate and bicarbonate resin, all of the original peroxide could not be accounted for, as was also the case with the hydroxide resin. This is shown in Figure 3, which shows that the rate of peroxide loss decreases with the decreasing basicity of the resin, the same order as given above. 


\section{DECOMPOSITION OF HYDROGEN PEROXIDE ABSORBED BY ANION EXCHANGE RESIN}

Work described in the previous sections revealed that decomposition of the peroxide proceeded in the presence of IRA-400, and that it probably occurred after the peroxide was absorbed by the resin. To confirm this 1dea, the disappearance of $\mathrm{H}_{2} \mathrm{O}_{2}$ was observed from resin that was inftially "saturated" with $\mathrm{H}_{2} \mathrm{O}_{2}$. Although the decomposition also proceeded with the carbonate and bicarbonate forms, only the hydroxide form was investigated since for this form the effect was much more pronounced.

\section{A. "Amberlite" IRA-400-OH and XE-150}

Experimental -- Samples of $0.74 \mathrm{ml}$ resin $10.5 \mathrm{~g}$ IRA-400-OH or $0.54 \mathrm{~g}$ XE-150) were stirred with $25 \mathrm{ml}$ of $0.1 \mathrm{M} \mathrm{H}_{2} \mathrm{O}_{2}$ for three minutes at room temperature. This dilute solution and short contact time were adopted in order to avoid degrading the resin. Then the supernate was decanted and the resin washed by swirling it for 30 seconds in 1ce cold water*. The reduced temperature diminished the rate of decomposition of the absorbed $\mathrm{H}_{2} \mathrm{O}_{2}$. The water wash was decanted and the moist resin was placed in a constant temperature bath for the designated time. Tubes containing "Ascarite" were used to protect the resin from $\mathrm{CO}_{2}$ in the air.

At the end of the designated time the peroxide was washed out of the resin by stirring it with about $25 \mathrm{ml} 1 \% \mathrm{H}_{2} \mathrm{SO}_{4}$ for 15 minutes at room temperature. The wash was decanted and its peroxide content determined by the colorimetric method described in the Appendix.

In one test the decomposition was followed by measuring the evolution of gas at room temperature $\left(24.5^{\circ} \mathrm{C}\right)$, from a sample of resin saturated with peroxide. This was done by displacing mercury from a gas buret at atmospheric pressure.

Results and Discussion -- Curves for isothermal decomposition of the peroxide absorbed on IRA $-400-0 H$ and $\mathrm{XE}-150$ are presented in Figures 6 and 7 . The data have been interpreted in terms of a reaction first order with respect to $\mathrm{H}_{2} \mathrm{O}_{2}$, and they fit this interpretation fairly well above about 0.2 mole $\mathrm{H}_{2} \mathrm{O}_{2}$ /equivalent of resin. Below this concentration the rate of decomposition increases abruptly. No kinetic interpretation of this leg of the curve was attempted because of the low concentrations of peroxide involved and the lack of precision in the analyses.

*Two cases in which the resin was not washed are indicated in Figure 6 . There is little difference between results with washed and unwashed resin at $24.5^{\circ} \mathrm{C}$. 
In order to compare the two resins, the rate constants for first order reactions and their activation energies were calculated for the early decomposition by conventional methods. These numbers are presented in Table III. The rate of decomposition was lower for the mixed resin than for the IRA-400-OH alone. No explanation can be offered for this difference in rate apart from a possible stabilizing influence exerted by the acid resin beads. The effect of the presence of other materials on decomposition rate is discussed later in this section. The activation energies, $E_{A}$, for the decomposition on the two resins are similar, which indicates the mechanisms are probably also similar. The values of $\mathrm{E}_{\mathrm{A}}, 18$ and $22 \mathrm{kcal} / \mathrm{mole}$, are in the same range as those found in other studies of peroxide decomposition $(\sigma)$.

The abrupt increase in decomposition rate below about 0.2 mole $\mathrm{H}_{2} \mathrm{O}_{2}$ /equivalent of resin occurred for both the IRA-400 and the XE-150. A similar abrupt increase in rate was observed by Doyle who studied the decomposition rate of 5 wt $\%$ hydrogen peroxide $(\sigma)$ as a function of $\mathrm{pH}$. He found that the rate of decomposition increased abruptly above $\mathrm{pH}$ 8.7. In the resin system, a rise in $\mathrm{pH}$ may accompany the peroxide decomposition, If the peroxide is held lonically, as discussed in section $V$. Thus in the resin there may be a critical peroxide concentration below which the decomposition rate increases because of an attendant rise in $\mathrm{pH}$.

Also included in Figure 6 are the results of a study in which the evolution of gas was taken as a measure of decomposition. The good agreement between this curve and the one determined by chemical. analysis indicates the peroxide decomposition proceeds with the stolchiometric release of oxygen, and side reactions are not significant.

\section{B. Decomposition in Presence of Other Resins}

Experimental -- The IRA-400-OH resin was first saturated with $\mathrm{H}_{2} \mathrm{O}_{2}$ by the method described above. Then either IR-120-H or polystyrene beads were added with the 30-second cold water wash. After the wash was decanted the moist resin mixture was allowed to sit at $30^{\circ} \mathrm{C}$ for a specified time. At the end of this time the mixture was washed w1th about $25 \mathrm{ml} 1 \% \mathrm{H}_{2} \mathrm{SO}_{4}$ and the $\mathrm{H}_{2} \mathrm{O}_{2}$ content of the wash determined colorimetrically.

Results and Discussion -- The results are given in Table IV, where $1 t$ can be seen that the presence of IR-120-H decreases the decomposition rate considerably, and that the presence of polystyrene beads (Inert material) has a somewhat lesser effect. The effect of IR-120-H conflrms the results obtained earlier, in which the rate of decomposition was observed to be slower in a mixed resin than in IRA-400-OH alone. 


\section{MECHANISM OF HYDROGEN PEROXIDE ABSORPTION ON IRA-400-OH}

During the course of this work, considerable indirect evidence that the absorption of peroxide on IRA-400-OH is an ion exchange process has accumulated. That is, 1 is suggested that the weak acid, $\mathrm{H}_{2} \mathrm{O}_{2}$, is neutralized by the hydroxide resin, with the formation of the hydroperoxide form of the resin. It is proposed that the hydroperoxide resin subsequently decomposes, regenerating hydroxide resin and emitting oxygen gas.

The reactions proposed are expressed by the following equations:

$$
\begin{aligned}
& \mathrm{ROH}+\mathrm{H}_{2} \mathrm{O}_{2} \rightarrow \mathrm{RO}_{2} \mathrm{H}+\mathrm{H}_{2} \mathrm{O} \\
& \mathrm{RO}_{2} \mathrm{H} \rightarrow \mathrm{ROH}+\frac{1}{2} \mathrm{O}_{2}
\end{aligned}
$$

No way to confirm this idea directly has been found. In this section the various pleces of evidence that support this theory are reviewed.

\section{A. Removal of Hydrogen Peroxide from IRA-400-OH}

Previous experiments had shown that more peroxide could be washed from the resin by sulfuric acid than by water. Additional experiments, designed to compare the effectiveness of various reagents for washing the absorbed $\mathrm{H}_{2} \mathrm{O}_{2}$ from the resin, are discussed below.

Experimental -- Resin was saturated with peroxide as described previously. After saturation the resin was swirled for 30 seconds with $25 \mathrm{ml}$ 1ce cold water to remove peroxide held by Donnan absorption. The peroxide content of this wash was determined. Then the resin was stirred with elther $1 \% \mathrm{H}_{2} \mathrm{SO}_{4}, 1 \% \mathrm{Na}_{2} \mathrm{SO}_{4}$, or $\mathrm{H}_{2} \mathrm{O}$ for 15 minutes at room temperature, and the peroxide content of this wash determined.

Results and Discussion -- In Table $\mathrm{V}$ it is seen that more peroxide was washed from the resin by the electrolyte solutions than by water alone. After the water wash, considerably more peroxide could be removed by washing with acid. From this, it was concluded that the peroxide was held ionically on the resin, and that $1 t$ was removable only by ion exchange.

Comparison of the effectiveness of the reagents is only qualitative, since the experiment was complicated by the decomposition of the peroxide during the washing operations. That is, decomposition proceeded at room temperature in the case of the water and the $\mathrm{Na}_{2} \mathrm{SO}_{4}$ washes, since the system is alkaline, whereas the acid wash effectively quenched the decomposition reaction. An estimate of the amount of peroxide that decomposed during the water wash is included in Table V. From the data at hand, no estimate can be made of the amount of decomposition that occurred during the $\mathrm{Na}_{2} \mathrm{SO}_{4}$ washing. 


\section{B. Absorption from Solution; Equilibrium Quotient}

Only the hydroxide form of the anion resin absorbs peroxide to any great extent. This is 1llustrated in Figure 4 where it is shown that the amount of peroxide absorbed decreased markedly when the carbonate, bicarbonate, or chloride form was used instead of the hydroxide. This can be expla1ned by the occurrence of a neutralization reaction. That is, the weak acid was neutralized by the alkaline resin, with the formation of water.

Furthermore it was not possible to obtain absorption of peroxide, not removable by water wash, in excess of one mole $\mathrm{H}_{2} \mathrm{O}_{2}$ /equivalent of resin. This suggests a stolchiometric reaction.

Equilibrium quotients, defined in Equation (7) below, were calculated from the data in Figure 2 for absorption of peroxide from $10^{-2}, 10^{-3}$, and $10^{-4} \mathrm{M}$ solutions. As explained in section III, the leveling-off in the absorption curves is attributed to the attainment of an equilibrium distribution of peroxide between resin and solution phases. The peroxide concentrations used in the calculations were those after a contact time of five minutes, at which the curve has leveled off. It was assumed that the following equilibria occurred:

$$
\begin{array}{rlrl}
\mathrm{H}_{2} \mathrm{O}_{2} & \rightleftarrows \mathrm{H}^{+}+\mathrm{O}_{2} \mathrm{H}^{-} & \mathrm{K}_{\mathrm{p}} & =2.24 \times 10^{-12} \text { at } 25^{\circ} \mathrm{C}^{(6)} \\
\mathrm{ROH}+\mathrm{O}_{2} \mathrm{H}^{-} & \rightleftarrows \mathrm{RO}_{2} \mathrm{H}+\mathrm{OH}^{-} & \mathrm{K}_{\mathrm{e}}=\frac{\left(\mathrm{RO}_{2} \mathrm{H}\right)}{(\mathrm{ROH})} \frac{\left(\mathrm{OH}^{-}\right)}{\left(\mathrm{O}_{2} \mathrm{H}^{-}\right)} \\
\mathrm{H}_{2} \mathrm{O} & \rightleftarrows \mathrm{H}^{+}+\mathrm{OH}^{-} & \mathrm{K}_{\mathrm{W}}=10^{-14} \text { at } 25^{\circ} \mathrm{C}
\end{array}
$$

The calculated equilibrium quotients are given in Table VI. The average value of 1.5 is a reasonable one, since the similarity of peroxide and water would lead one to expect an equilibrium constant near unity.

\section{Effect on $\mathrm{pH}$}

The $\mathrm{pH}$ of a water slurry of IRA-400-OH that has been treated with $\mathrm{H}_{2} \mathrm{O}_{2}$ is lower than that of the same resin untreated. This indicates something has happened to the hydroxide groups of the resin. In Figure 8 it is seen that over a perlod of several hours the pH of the slurry of peroxide-treated resin increased. After sitting overnight it attained the $\mathrm{pH}$ value of the slurry of the untreated resin. This indicates that the hydroxide groups on the resin have been regenerated.

The measurements were made while the resin was stirred in water. The $\mathrm{pH}$ of the slurry was determined by means of a pH meter, with glass and calomel electrodes. 


\title{
VI. HYDROGEN PEROXIDE REMOVAL BY RESINS IN A MINIATURE PURIFICATION LOOP
}

The laboratory observation that only the hydroxide form of the anion exchange resin absorbed peroxide to any great extent was confirmed in a miniature purification loop in which irradiated water was passed in parallel through columns of ion exchange resins. Two of the resin columns contained mixed resin in the $\mathrm{H}-\mathrm{OH}$ form; the third, mixed resin in the $\mathrm{H}-\mathrm{CO}_{3}$ form. The peroxide contents of the influent and effluents during operation are given in Table VII, which shows that the first two columns removed peroxide, but that the third $\left(\mathrm{H}-\mathrm{CO}_{3}\right)$ did not. When the columns were nearly exhausted, the peroxide was no longer removed in any of the columns. It is not known why the peroxide content of the effluent from the third column is higher than the influent.

This experience suggests an explanation for the conflicting results reported from Chalk River(2,3). In the latter reference it was stated that the resins tested may have been in the carbonate form, although this was not verified. It is demonstrated above that only the hydroxide form can effectively remove hydrogen peroxide from solution.

\author{
L.W. Bacumean \\ E. W. Baumann \\ Pile Engineering Division
}




\section{APPENDIX}

\section{PREPARATION AND ANALYSIS OF RESINS}

\section{Preparation of Resins}

IRA-400-OH -- The "Amberlite" IRA-400, nominally in the hydroxide form as recelved from the vendor*, was further regenerated by passing $\mathrm{CO}_{2}$-free**, $10 \% \mathrm{NaOH}$ through a column of resin. The resin was washed free of excess hydroxyl and partlally dried in a stream of $\mathrm{CO}_{2}$-free air.

IRA-400- $\mathrm{CO}_{3}$-- The "Amberlite" IRA-400 as recelved was converted to the carbonate form by passing a solution of $10 \% \mathrm{Na}_{2} \mathrm{CO}_{3}$ through a column of resin, until the resin was exhausted. The resin was washed free of excess carbonate, and partially dried in a stream of $\mathrm{CO}_{2}$-free a1r.

IRA -400- $\mathrm{HCO}_{3}$-- The "Amberlite" IRA-400 as received was converted to the bicarbonate form by passing a solution of $10 \% \mathrm{NaHCO}_{3}$ through a column of resin, to exhaustion. The resin was washed free of excess bicarbonate and partially dried in a stream of air.

IRA-400-CI -- The "Amberl1te" IRA-400 as recelved was converted to the chloride form by the method described above, using $20 \% \mathrm{NaCl}$ as eluant.

IR-120-H -- This resin was used in the hydrogen form as received from the vendor*.

XE-150 -- This was used in the $\mathrm{H}-\mathrm{OH}$ form, as received from Rohm and Haas, the manufacturer.

Polystyrene beads -- This is a special material furnished by Rohm and Haas, consisting of the polystyrene-divinylbenzene copolymer that is an intermediate in the ion exchange synthesis. The particle size was 20 to 50 mesh.

* Illinols Water Treatment Company, Rockford, Illinols

* Th1s was accomplished by using a protective column of IRA-400-0H through which the $\mathrm{NaOH}$ passed before passing into the resin to be regenerated. This protective column removes carbonate and other impurities from the solution. 


\section{Analysis of Resins}

Exchange Capacity of Anion Exchange Resins -- The salt-splitting capacity of the hydroxide resin was determined by means of a titration curve. That is, a weighed amount of molst resin was placed in $100 \mathrm{ml} \mathrm{10 \%} \mathrm{NaCl}$ and titrated with standardized $0.1 \mathrm{~N} \mathrm{HCl}$.

The ultimate capacity was determined by the method of Fisher and Kunin $(8)$. The resin was converted to the chloride form by washing with $\mathrm{HCl}$, the chloride was eluted from the resin with $\mathrm{Na}_{2} \mathrm{SO}_{4}$, and the amount of chloride was determined by a Mohr titration.

Exchange Capacity of Cation Exchange Resins -- The cation exchange resin was placed in $100 \mathrm{ml} 10 \% \mathrm{NaCl}$ and the slurry titrated to an end point of 7.2 with standardized $0.1 \mathrm{~N} \mathrm{NaOH}$.

\section{PREPARATION AND ANALYSIS OF HYDROGEN PEROXIDE SOLUTIONS}

\section{Preparation}

The hydrogen peroxide used for these experiments was $30 \% \mathrm{H}_{2} \mathrm{O}_{2}$, a laboratory reagent from Fisher Chemical Company. It is stabilized by sodium stannate in an amount estimated to be less than $50 \mathrm{ppm}$. Peroxide solutions of the required concentration were prepared by appropriate dilution with deionized water.

\section{Analysis for Peroxide}

a. Volumetric Method

The peroxide concentration of solutions $0.05 \mathrm{M}$ and higher was determined by a standard lodometric method ${ }^{(\theta)}$.

\section{b. Colorimetric Method}

The solutions of low peroxide content were diluted to $25 \mathrm{ml}$, and the peroxide content of an aliquot determined by the method described by Allen (10) in which the absorbance of lodine freed by peroxide is determined. Appropriate blank determinations were made.

\section{METHOD FOR CHEMICAL OXYGEN DEMAND}

This method, described in Reference (11), was modifled by using $0.1000 \mathrm{~g}$ solid $\mathrm{K}_{2} \mathrm{Cr}_{2} \mathrm{O}_{7}$, rather than a solution, in order to minimize dilution of the oxidizing mixture. The method consists of oxidizing organic matter in acid that contains a known amount of $\mathrm{K}_{2} \mathrm{Cr}_{2} \mathrm{O}_{7}$. The $\mathrm{K}_{2} \mathrm{Cr}_{2} \mathrm{O}_{7}$ remaining after the oxidation is determined by titration with standardized ferrous ammonium sulfate. 


\section{BIBLIOGRAPHY}

1. Rynasiew1cz, Joseph. "Hydrogen Peroxide Determination in the Presence of Chromate". Anal. Chem. 26, 355-8 (1954). No. 2, February.

2. Heal, H. G., et a1. Decomposition of Heavy Water Under Reactor Irradiation (The "Cold Loop" Experiment). Atomic Energy of Canada, Ltd., Chalk River Project, Chalk River, Ont. CRC-494, $39 \mathrm{pp}$. (February 1952) (Classification changed to Officlal Use Only May 1956).

3. Krenz, F. H. and R. F. S. Robertson. Chemical Aspects of the NRU Test Loop. Atomic Energy of Canada, Ltd., Chalk River Project, Chalk River, Ont. CRC-544, $96 \mathrm{pp.}$ (June 1953) (Classification changed to Official Use Only May 1956).

4. Technical Progress Report, Pressurized Water Reactor (PWR) Project, December 24, 1956, to February 23, 1957. Westinghouse, Bett1s Plant, P1ttsburgh, Pa. AEC Research and Development Report WAPD-MRP-66, $77 \mathrm{pp}$.

5. Wood, W. "Stablilty of Sulfonated Cross-Linked Ion Exchange Resin in Hydrogen Peroxide". J. Phys. Chem. 61, 832 (1957). No. 6, June.

6. Schumb, W. C., C. N. Satterfield, and R. L. Wentworth. Hydrogen Peroxide. A.C.S. Monograph 128. New York: Reinhold Publishing Corporation (1955) (759 pp.).

7. Baumann, E. W. "Thermal Decomposition of "Amberlite" IRA-400." To be published in J. Chem. Eng. Data.

8. Fisher, S. and R. Kunin. "Routine Exchange Capacity Determinations of Ion Exchange Resins". Anal. Chem. 27, 1191-4 (1955). No. 7, July.

9. Kolthoff, I. M. and E. B. Sandel1. Textbook of Quantitative Inorganic Analysis, Third Edition, p. 600. New York: The MacMilian Company (1952) (759 pp.).

10. Allen, A. O., et al. Decomposition of Water and Aqueous Solutions Under Pile Radiation. Oak Ridge National Lab., Oak Ridge, Tenn. AEC Research and Development Report ORNL-130, $63 \mathrm{pp.}$ (October 1949) (Declassifled March 7, 1957).

11. Standard Methods for the Examination of Water, Sewage, and Industrial Wastes, Tenth Edition, pp. $332 \mathrm{ff}$. New York: American Public Health Association, Inc. (1955) (522 pp.). 


\section{TABLEI}

EFFECT OF HYDROGEN PEROXIDE ON ION EXCHANGE RESINS

(Resin and $100 \mathrm{ml} 0.05 \mathrm{M} \mathrm{H}_{2} \mathrm{O}_{2}$ in contact for 2 hours)

Resin

Resin
$1.1 \mathrm{~g}$ IR-120-H
$2.0 \mathrm{~g}$ IRA $-400-\mathrm{OH}$
$1.0 \mathrm{~g}$ IRA $-400-\mathrm{HCO}_{3}$
$1.0 \mathrm{~g}$ IRA-400- $\mathrm{CO}_{3}$
$1.0 \mathrm{~g}$ XE-150
$1.0 \mathrm{~g}$ Polystyrene beads

$$
\text { Salt-Splitting Capacity, }
$$
$\mathrm{meg} / \mathrm{g}$ Initial

2.492 .48

$1.54 \quad 1.41$

1.621 .62

$1.56 \quad 1.51$

Not determined

None None

$\mathrm{H}_{2} \mathrm{O}_{2}$ Concentration,
moles/liter

\section{TABLE II}

RELEASE OF ORGANIC MATTER FROM RESIN BY PEROXIDE TREATMENT (2-hour contact time)

\begin{tabular}{ll}
$\begin{array}{c}\text { Treatment of } \\
2.0 \mathrm{~g} \text { IRA-400-OH }\end{array}$ & $\begin{array}{c}\text { Chemical Oxygen Demand of } \\
\text { Supernatant IIquid, } \\
\text { meg/g resin }\end{array}$ \\
\hline $100 \mathrm{ml} \mathrm{H}_{2} \mathrm{O}$ (Blank) & 0.075 \\
First contact with $100 \mathrm{ml}$ & 0.146 \\
$0.05 \mathrm{M} \mathrm{H}_{2} \mathrm{O}_{2}$ & 0.092 \\
Second contact with $100 \mathrm{ml}$ & \\
$0.05 \mathrm{M} \mathrm{H}_{2} \mathrm{O}_{2}$ & 0.063 \\
Th1rd contact with $100 \mathrm{mI}$ \\
$0.05 \mathrm{M} \mathrm{H}_{2} \mathrm{O}_{2}$
\end{tabular}




\section{TABLE III}

KINETIC DATA FOR DECOMPOSITION OF HYDROGEN PEROXIDE ABSORBED ON RESINS

\begin{tabular}{|c|c|c|c|}
\hline \multirow[b]{2}{*}{ Resin } & \multirow[b]{2}{*}{$\mathrm{T},{ }^{\circ} \mathrm{K}$} & $\left(c / \mathrm{Co}^{(\mathrm{a})}>0.2\right)$ & \multirow[b]{2}{*}{$\begin{array}{l}\mathrm{E}_{\mathrm{A}}=\mathrm{R}\left(\frac{\mathrm{d} \ln \mathrm{k}^{(\mathrm{b})}}{\mathrm{d} \operatorname{l} / \mathrm{T}}\right) \\
\mathrm{kcal} / \mathrm{mole} \\
\end{array}$} \\
\hline & & $\begin{array}{c}\text { Half-l1fe, } \\
h r\end{array}$ & \\
\hline IRA $-400-O H$ & 297.7 & 2.70 & \\
\hline IRA $-400-0 H$ & 303.2 & 0.72 & \\
\hline IRA $-400-O H$ & 313.2 & 0.36 & 22 \\
\hline$X E-150$ & 303.2 & 1.56 & \\
\hline$X E-150$ & 313.2 & 0.56 & 18 \\
\hline
\end{tabular}

\section{TABLE IV}

INFLUENCE OF OTHER RESINS ON DECOMPOSITION OF HYDROGEN PEROXIDE ABSORBED ON IRA -400-OH

$$
\left(\mathrm{T}=30^{\circ} \mathrm{C}\right)
$$

\begin{tabular}{l} 
Resin Added to \\
$0.5 \mathrm{~g}$ IRA-400-OH \\
\hline
\end{tabular}

Nothing

0.5 \& Polystyrene beads

$0.35 \mathrm{~g}$ IR $-120-\mathrm{H}$
Fraction of Original $\mathrm{H}_{2} \mathrm{O}_{2}$ Left After 1 hour 2 hours

0.2230 .0004

0.2360 .0013

$0.254 \quad 0.0084$ 


\section{TABLE V}

WASHING OF HYDROGEN PEROXIDE FROM IRA-400-OH

(Pretreatment: $0.5 \mathrm{~g}$ IRA $-400-0 \mathrm{H}$ stirred 3 minutes with $25 \mathrm{ml} 0.1 \mathrm{M} \mathrm{H}_{2} \mathrm{O}_{2}$ )

Sample

A
Washing

30 seconds with ice cold water

15 minutes with water at $25^{\circ} \mathrm{C}$

15 minutes with $1 \% \mathrm{H}_{2} \mathrm{SO}_{4}$ at $25^{\circ} \mathrm{C}$

$\mathrm{H}_{2} \mathrm{O}_{2}$ decomposed during water

wash (estimated from Figure 6)

30 seconds with ice cold water

15 minutes with $1 \% \mathrm{H}_{2} \mathrm{SO}_{4}$ at $25^{\circ} \mathrm{C}$

30 seconds with 1ce cold water

15 minutes with $1 \% \mathrm{Na}_{2} \mathrm{SO}_{4}$ at $25^{\circ} \mathrm{C}$
$\mathrm{H}_{2} \mathrm{O}_{2}$ in Wash, moles $\underline{\mathrm{H}_{2} \mathrm{O}_{2} / \text { equivalent of resin }}$

\subsection{3}

0.060

0.535

0.174

0.149

0.834

Not determined

0.697

\section{TABLE VI}

EQUILIBRIUM ABSORPTION OF HYDROGEN PEROXIDE ON IRA-400-OH

$\mathrm{H}_{2} \mathrm{O}_{2}$ Content

of Original

Solution, moles/liter

$$
10^{-4}
$$

$10^{-3}$

$10^{-2}$
$\frac{\mathrm{H}_{2} \mathrm{O}_{2} \text { Content at Equilibrium }}{\text { Solution phase, Resin phase, }}$ moles/liter

$$
6.4 \times 10^{-6}
$$$$
7.8 \times 10^{-5}
$$

$1.25 \times 10^{-3}$ millimoles

$1.35 \times 10^{-3}$

$1.42 \times 10^{-2}$

$1.62 \times 10^{-1}$ $\alpha$, degree of

dissociation

$\frac{\text { of } \mathrm{H}_{2} \mathrm{O}_{2}}{2.24 \times 10^{-5}} \frac{\mathrm{Ke}^{(\mathrm{b})}}{1.6}$

$2.24 \times 10^{-5}$

$1.97 \times 10^{-5}$

1.6

1.4

1.4

(a) Exchange capacity of resin sample is $0.576 \mathrm{meq}$

(b) $\mathrm{K}_{e}=\left[\frac{\mathrm{millimoles} \mathrm{H}_{2} \mathrm{O}_{2} \text { in res } 1 \mathrm{n}}{0.576-\text { millimole } \mathrm{H}_{2} \mathrm{O}_{2}}\right]\left[\frac{\text { molarity of } \mathrm{OH}}{\left(\text { molarity of } \mathrm{H}_{2} \mathrm{O}_{2}\right)(a)}\right]$ 


\section{TABLE VII}

HYDROGEN PEROXIDE REMOVAL BY RESINS IN A MINIATURE PURIFICATION LOOP

\begin{tabular}{|c|c|c|c|c|}
\hline Influent & $\begin{array}{c}\text { Effluent } \\
\text { No. } 1 \\
\text { (H-OH resin) } \\
\end{array}$ & $\begin{array}{c}\text { Effluent } \\
\text { No. } 2 \\
\text { (H-OH resin) } \\
\end{array}$ & $\begin{array}{c}\text { Effluent } \\
\mathrm{No} \cdot 3 \\
\left(\mathrm{H}-\mathrm{CO}_{3} \text { resin) }\right. \\
\end{array}$ & Comments \\
\hline 8.9 & 0.8 & 0.7 & 9.4 & \\
\hline 1.1 & 0.2 & 0.2 & 0.4 & \\
\hline 2.0 & 0.1 & $<0.1$ & 4.2 & \\
\hline 1.7 & 0.7 & 0.6 & 2.6 & \\
\hline 0.6 & 0.7 & 0.6 & 2.1 & Nearly exhausted \\
\hline 4.7 & 4.8 & 5.2 & 5.6 & Exhausted \\
\hline
\end{tabular}




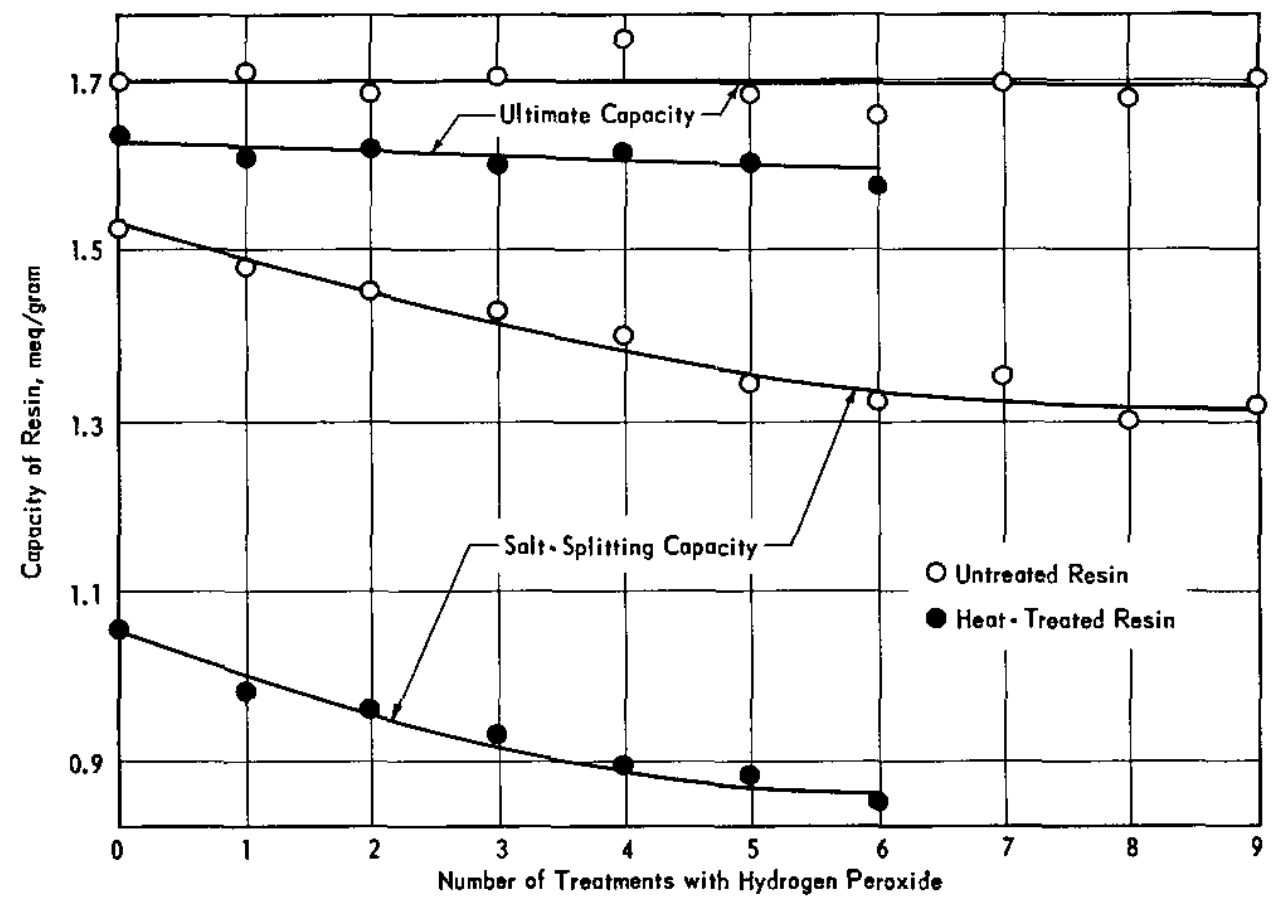

FIG. I REPEATED TREATMENT OF IRA-400-OH WITH 0.05 M HYDROGEN PEROXIDE 2.0 Grams Resin and $100 \mathrm{Ml} 0.05 \mathrm{M}$ Hydrogen Peroxide in Contact 2 Hours 


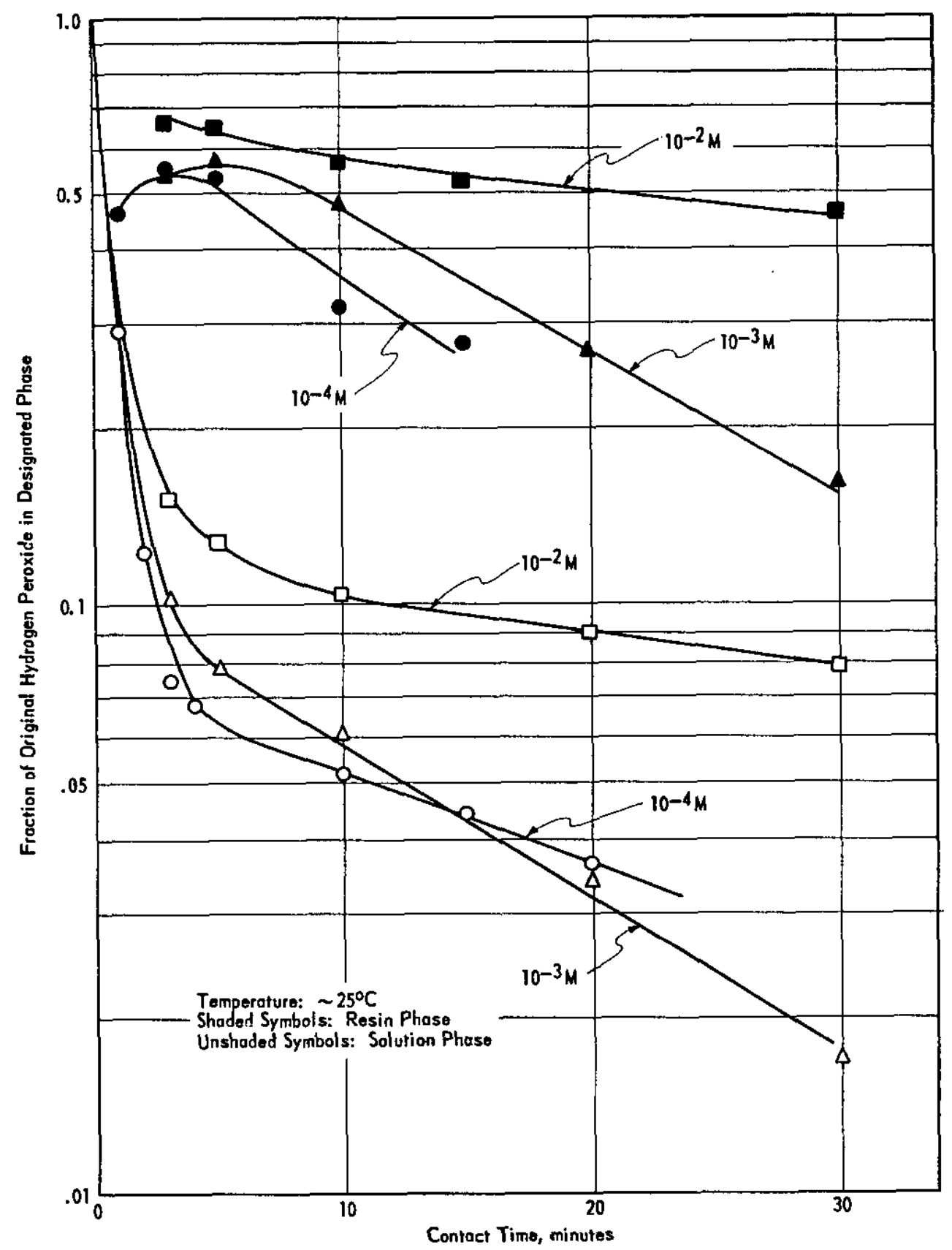

FIG. 2 HYDROGEN PEROXIDE SOLUTION IN CONTACT WITH IRA-400-OH $0.5 \mathrm{Gram}$ Resin and $25 \mathrm{Ml}$ Solution 


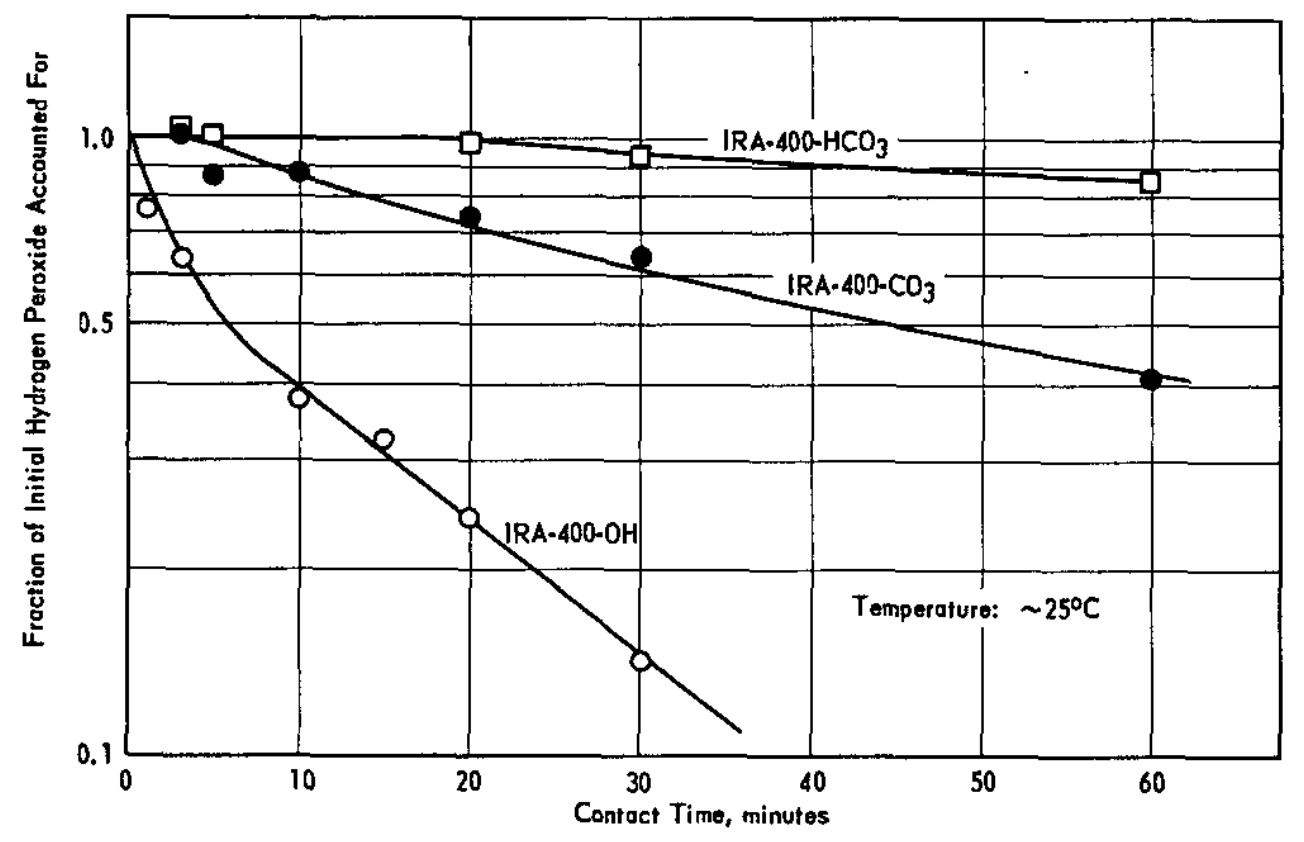

FIG. 3 MATERIAL BALANCE OF HYDROGEN PEROXIDE IN RESIN-SOLUTION MIXTURES $0.74 \mathrm{Ml}$ Rosin and $25 \mathrm{Ml} \mathrm{10^{-4 }} \mathrm{M}$ Hydrogen Poroxide

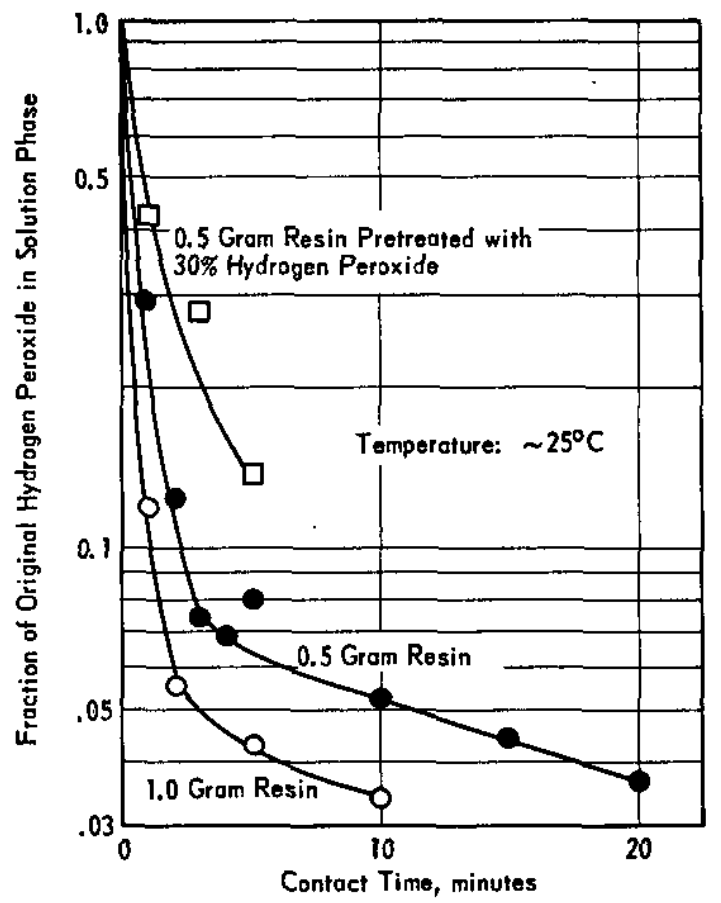

FIG. 4 HYDROGEN PEROXIDE SOLUTION IN CONTACT WITH IRA-400-OH $25 \mathrm{MI} 10^{-4} \mathrm{M}$ Hydrogen Peroxide 


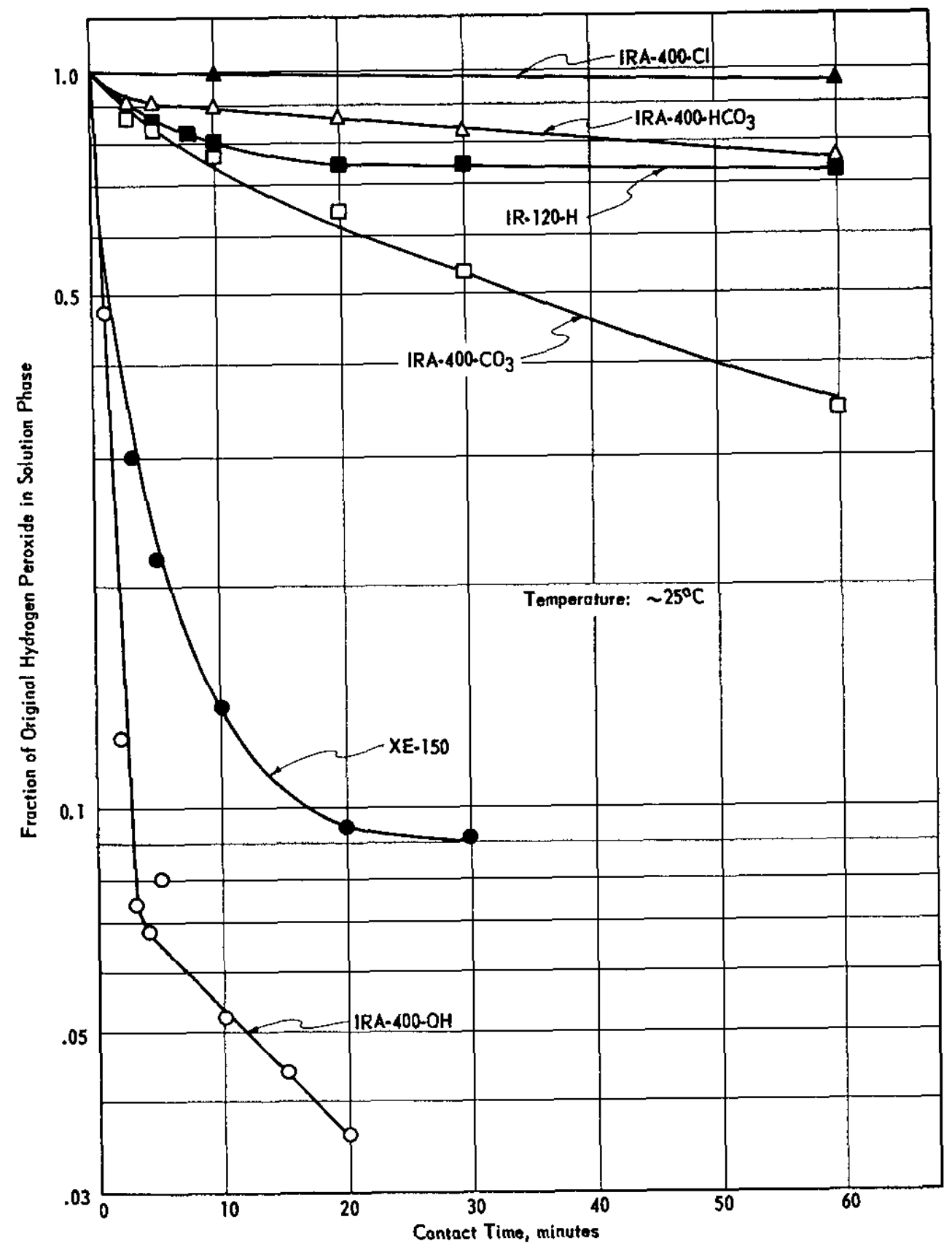

FIG. 5 HYDROGEN PEROXIDE SOLUTION IN CONTACT WITH VARIOUS RESINS $0.74 \mathrm{Ml}$ Resin and $25 \mathrm{Ml} \mathrm{10^{-4 }} \mathrm{M}$ Hydrogen Poroxide 


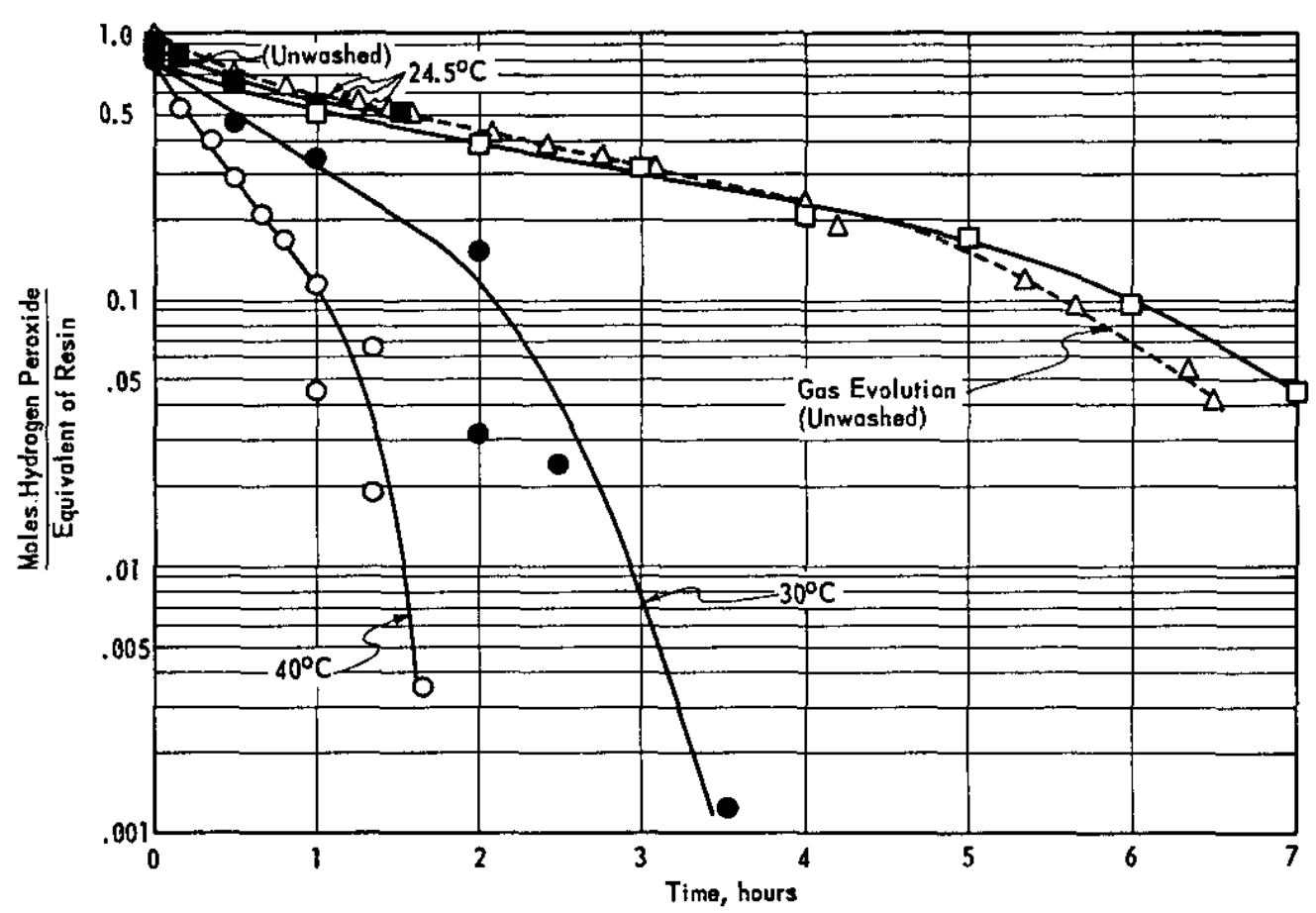

FIG. 6 DECOMPOSITION OF HYDROGEN PEROXIDE ABSORBED ON IRA-400-OH All Data Obtained by Chemical Analysis of Resin That Hod Beon

Prowashed, with the Exceptions Noted

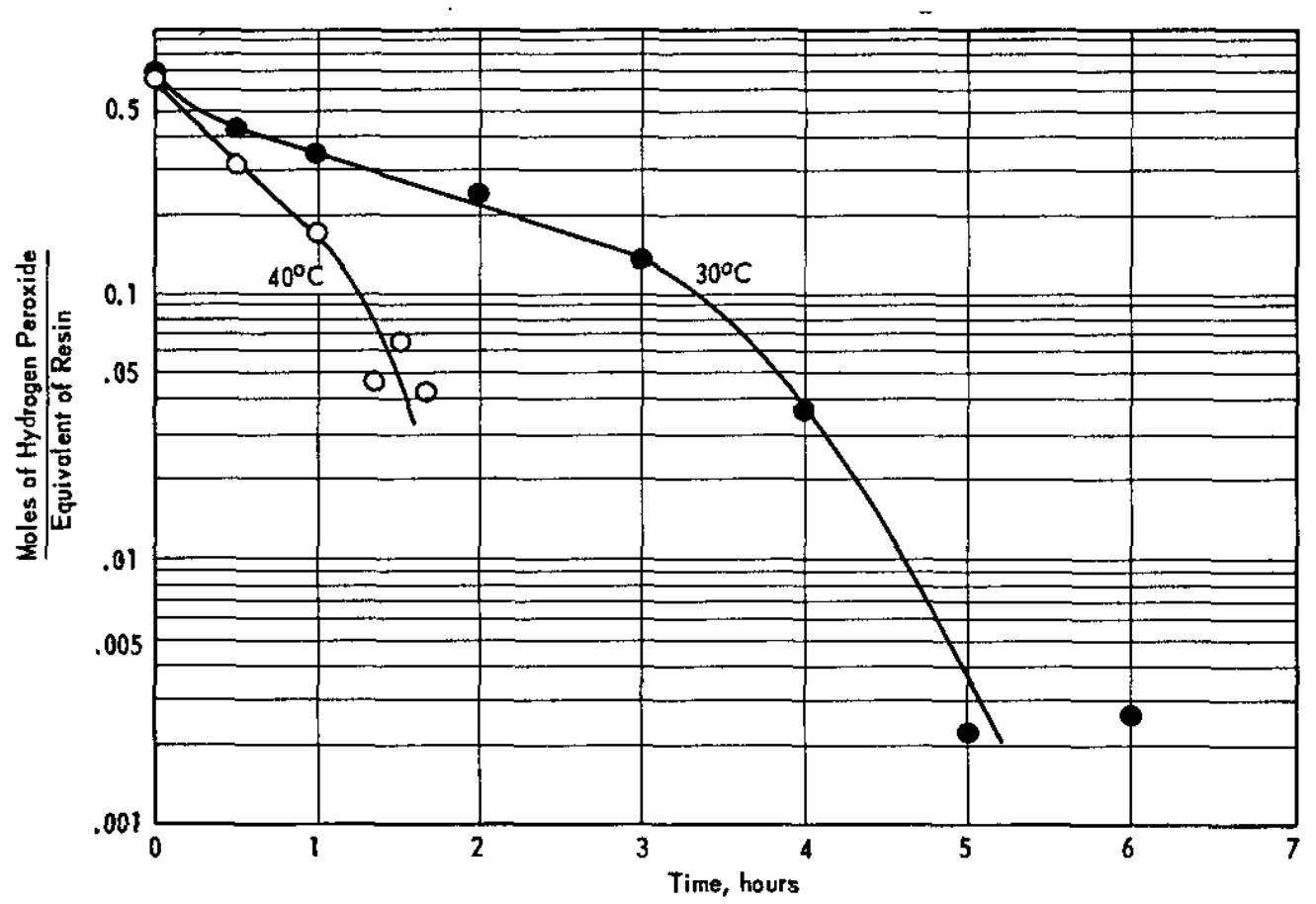

FIG. 7 DECOMPOSITION OF HYDROGEN PEROXIDE ABSORBED ON XE-150 

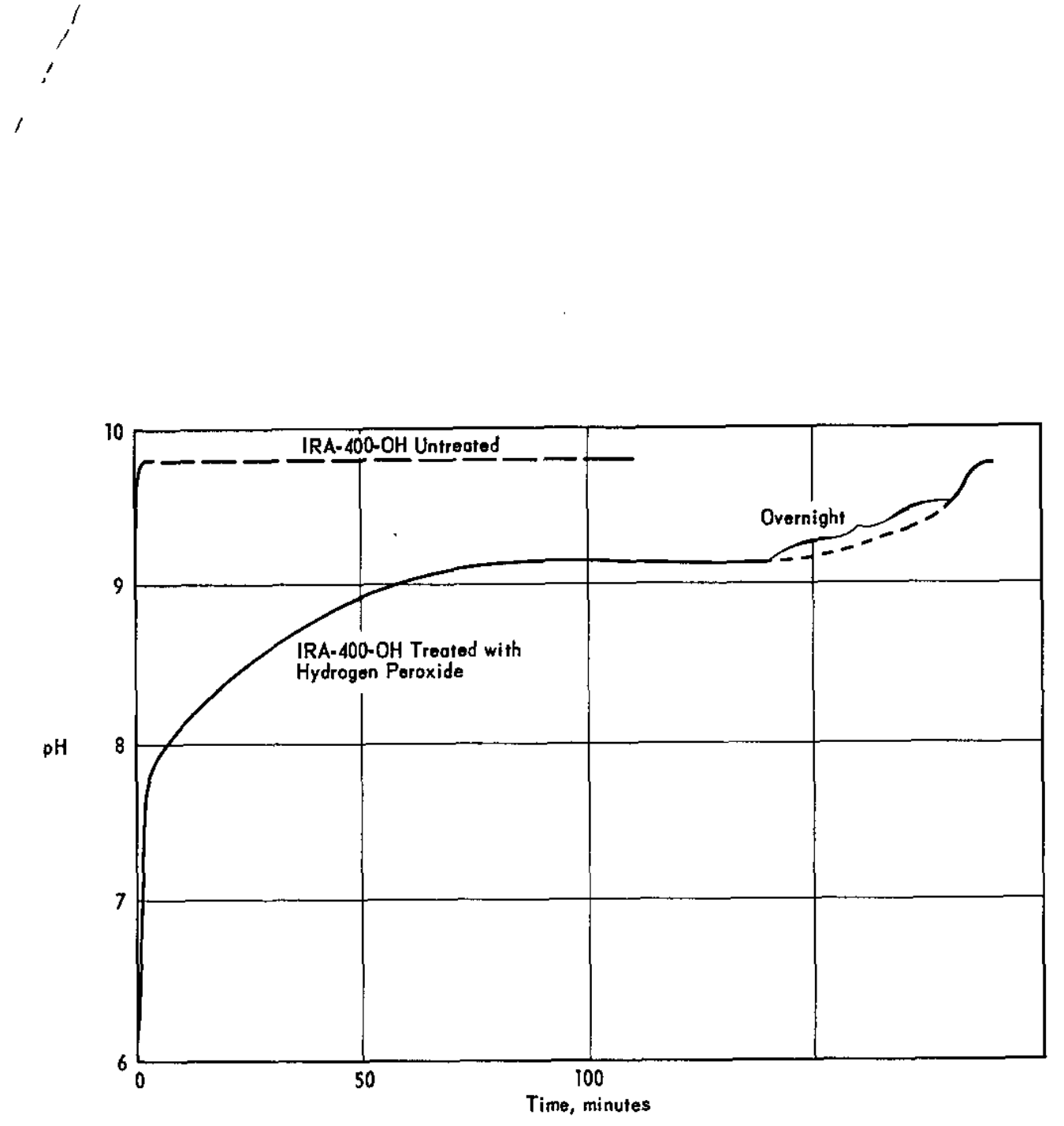

FIG. 8 PH OF RESIN SLURRY 